\title{
Whole grain Intakes in Irish Pre-school Children
}

\author{
C. Hamrock ${ }^{1}$, M. Buffini ${ }^{1}$, A.P. Nugent ${ }^{1,2}$, J. Walton ${ }^{3}$, A. Flynn ${ }^{3}$ and B.A. McNulty ${ }^{1}$ \\ ${ }^{1}$ UCD Institute of Food and Health, School of Agriculture and Food Science, University College Dublin, Belfield, \\ Dublin, Ireland, ${ }^{2}$ Institute for Global Food Security, School of Biological Sciences, Queens University Belfast, BT9 \\ $5 H N$ and ${ }^{3}$ School of Food and Nutritional Sciences, University College Cork, Cork, Ireland
}

Whole grain intake is associated with many health benefits and a reduced risk for many chronic diseases such as type 2 diabetes, cardiovascular disease, obesity and colorectal cancer ${ }^{(1,2)}$. Currently, no research exists profiling the whole grain intakes of Irish pre-school children however, this life stage is a fundamental time for the development of taste preferences and healthy food choices ${ }^{(3)}$. The aim of this study was to investigate the whole grain intakes of Irish pre-school children and to profile patterns of intake. Data was analysed from the National Pre-school Nutrition Survey (NPNS; n 500), which used a 4-day weighed food-intake diary; collecting data on habitual food and beverage intakes in a representative sample of 1-4 year olds (www.iuna.net). Brand information, including ingredient listings, was subsequently recorded in the Irish National Food Ingredient Database (INFID) ${ }^{(4)}$, with each brand linked to consumption data. In the current analysis, the presence or absence of whole grain was confirmed at food and brand level, and information on the grain ingredients present were ascribed using food package labelling, comparable products and recipe databases specific for the NPNS. Whole grain content was calculated as dry matter, whereby the water content $(\%)$ and the dry matter whole grain content (\%) of whole-grain ingredients were established.

Descriptive analysis of whole grain intake $(\mathrm{g} / \mathrm{d})$ for Irish pre-school children (total population and whole grain consumers only)

\begin{tabular}{|c|c|c|c|c|c|c|c|c|c|c|c|c|c|c|c|c|}
\hline & \multicolumn{8}{|c|}{ Total Population } & \multicolumn{8}{|c|}{ Whole grain consumers only } \\
\hline & $\mathrm{n}$ & $\%$ & Mean & Median & SD & P5.0 & P97.5 & $\mathrm{P}$ & $\mathrm{n}$ & $\%$ & Mean & Median & $\mathrm{SD}$ & P5.0 & P97.5 & $\mathrm{P}$ \\
\hline Total Population & 500 & 100 & $18 \cdot 43$ & $16 \cdot 05$ & $13 \cdot 36$ & $1 \cdot 40$ & $50 \cdot 72$ & & 485 & $97 \cdot 00$ & $19 \cdot 00$ & $16 \cdot 50$ & $13 \cdot 16$ & $2 \cdot 48$ & $50 \cdot 92$ & \\
\hline Gender & & & & & & & & $0 \cdot 051$ & & & & & & & & 0.093 \\
\hline Male & 251 & $50 \cdot 20$ & $19 \cdot 59$ & $16 \cdot 71$ & $14 \cdot 48$ & $1 \cdot 57$ & $57 \cdot 47$ & & 246 & $50 \cdot 72$ & 19.99 & $16 \cdot 88$ & $14 \cdot 35$ & $2 \cdot 50$ & $57 \cdot 59$ & \\
\hline Female & 249 & $49 \cdot 80$ & $17 \cdot 26$ & $15 \cdot 41$ & $12 \cdot 04$ & 0.43 & $47 \cdot 97$ & & 239 & $49 \cdot 28$ & $17 \cdot 98$ & $15 \cdot 87$ & 11.75 & $2 \cdot 47$ & $48 \cdot 10$ & \\
\hline Age & & & & & & & & $0 \cdot 031$ & & & & & & & & 0.022 \\
\hline 1 Year & 126 & $25 \cdot 20$ & $16 \cdot 06^{\mathrm{a}}$ & $13 \cdot 88$ & $11 \cdot 30$ & $2 \cdot 13$ & $50 \cdot 88$ & & 124 & $25 \cdot 57$ & $16 \cdot 32^{\mathrm{a}}$ & 13.89 & $11 \cdot 20$ & $2 \cdot 59$ & $50 \cdot 92$ & \\
\hline 2 Years & 124 & $24 \cdot 80$ & $18 \cdot 08^{\mathrm{ab}}$ & $16 \cdot 56$ & $12 \cdot 03$ & 1.27 & $48 \cdot 03$ & & 120 & $24 \cdot 74$ & $18 \cdot 68^{\mathrm{ab}}$ & $16 \cdot 65$ & 11.76 & 2.53 & $48 \cdot 08$ & \\
\hline 3 Years & 126 & $25 \cdot 20$ & $18 \cdot 57^{\mathrm{ab}}$ & $15 \cdot 46$ & $13 \cdot 73$ & 1.39 & $53 \cdot 23$ & & 119 & $24 \cdot 54$ & $19 \cdot 66^{\mathrm{ab}}$ & $16 \cdot 97$ & $13 \cdot 34$ & 2.40 & $54 \cdot 73$ & \\
\hline 4 Years & 124 & $24 \cdot 80$ & $21 \cdot 05^{\mathrm{b}}$ & $18 \cdot 50$ & $15 \cdot 65$ & 0.64 & $60 \cdot 89$ & & 122 & $25 \cdot 15$ & $21 \cdot 40^{\mathrm{b}}$ & $18 \cdot 55$ & $15 \cdot 54$ & 1.72 & $61 \cdot 23$ & \\
\hline
\end{tabular}

a,b Mean values with unlike superscript letters were significantly different between mean daily intakes of whole grain (ANOVA with Bonferroni post-hoc correction). Mean values were significantly different when $\mathrm{P}<0.05$

The mean daily intake of whole grain in the total population were $18.4 \mathrm{~g} / \mathrm{d}$, with $97 \%$ of pre-school children classified as consumers. Wheat sources contributed the most to whole grain intakes $(65.8 \%)$, followed by oats $(20.5 \%)$. Whereby 'Ready-to-eat breakfast cereals' $(50 \%)$ followed by 'bread and rolls' $(24.3 \%)$ provided the greatest contribution to whole grain intakes. Correspondingly, breakfast had the highest number of whole grain consumers $(91.8 \%, n=459)$. High consumers of whole grain had significantly higher intakes of fibre, iron, vitamin B12 and folate, and lower intakes of sodium $(\mathrm{p}<0.05)$. The present study shows that while a high proportion of pre-school children are whole grain consumers, overall dietary intakes are low. Development of an applicable recommendation is necessary for this age group as currently none exists.

This study was funded by the Irish Department of Agriculture, Fisheries and Food under the Food for Health Research Initiative (2007-2012).

1. Wu H, Flint AJ, Qi Q et al. (2015) JAMA Intern Med 175(3), 373-84.

2. Schatzkin A, Mouw T, Park Y et al. (2007) Am J Clin Nutr 85(5), 1353-60.

3. Cooke L (2007) J Hum Nutr Diet 20(4), 294-301.

4. Gilsenan MB, Lambe J, Gibney MJ (2002) Food Addit Contam 19(12), 1105-15. 